\title{
Thermal Stability and Kinetic of Decomposition of Mono- and Dicationic Imidazolium-Based Ionic Liquids
}

\author{
Caroline R. Bender, ${ }^{a, b}$ Bruna L. Kuhn, ${ }^{a}$ Carla A. A. Farias, ${ }^{a}$ Francieli I. Ziembowicz, ${ }^{c}$ \\ Thaíssa S. Beck ${ }^{a}$ and Clarissa P. Frizzo ${ }^{\circledR} * a$
}

${ }^{a}$ Núcleo de Química de Heterociclos (NUQUIMHE), Departamento de Química, Universidade Federal de Santa Maria (UFSM), 97105-900 Santa Maria-RS, Brazil

${ }^{b}$ Universidade Federal do Pampa (UNIPAMPA), 97650-000 Itaqui-RS, Brazil

${ }^{c}$ Laboratório de Espectroscopia e Polímeros (LEPOL), Departamento de Física, Universidade Federal de Santa Maria (UFSM), 97105-900 Santa Maria-RS, Brazil

\begin{abstract}
Phase transitions, thermal stability, thermokinetics and activation parameters of degradation reaction of the dicationic ionic liquids (ILs), 1,n-bis(3-methylimidazolium-1-yl)alkane ([BisAlk(MIM) $]$ [2Br]) and monocationic ILs, 1-(3-methylimidazolium-1-yl)alkane ([Alk(MIM)] $[\mathrm{Br}])$, where Alk = Dec, DoDec, TetDec, $($ decane, dodecane, tetradecane) were evaluated. The influence of an additional cationic head and the alkyl chain length in thermal parameters were also evaluated. The dicationic ILs are more stable than monocationic and thermal degradation of ILs mono- and dicationic did not show linear dependence on the alkyl chain length. Thermokinetic parameters indicated degradation in multiple steps. The monocationic ILs showed a more persistent crystalline phase than dicationic IL, which became totally amorphous after heating. The estimate temperature decomposition, activation energy and thermal transitions enable the determination of which types of ILs are applicable for specific purposes, such as lubricants or solvents at high temperatures, while maintaining ILs physical and chemical properties.
\end{abstract}

Keywords: ionic liquids, thermal decomposition, thermokinetics, activation parameters

\section{Introduction}

Ionic liquids (ILs) are structures broadly defined as organic salts with low melting points that have provoked interest due to their large thermal stability. ${ }^{1,2}$ Depending of the cation and anion combination, ILs may exhibit different physicochemical properties when compared with conventional electrolytes media or organic solvents. ${ }^{3-5}$ Properties such as high thermal stability, tunable electrochemical window, low flammability, broad liquid range, and ability to dissolve and stabilize a wide range of materials allow ILs to be used in engineered materials synthesis. Imidazolium-based ILs are among the most studied classes of ILs. Recently, dicationic imidazoliumbased ILs have emerged as a new option for applications because the insertion of an additional cationic head promotes decreased dicationic ILs toxicity when compared to their monocationic analogs. ${ }^{6,7}$ These ILs can act as

*e-mail: clarissa.frizzo@gmail.com advanced catalysts, ${ }^{8,9}$ surfactants, ${ }^{5,10}$ lubricants, ${ }^{11,12}$ and nanoparticle coating. ${ }^{13}$ Nevertheless, these processes are strongly temperature-dependent since both quality and yields are enhanced by operating at high temperatures. ${ }^{3,14}$ The lack of information regarding ILs thermal stability is a major barrier to the utilization of these compounds in engineering applications. Some studies have focused on determining the thermal behavior by thermogravimetric analysis (TGA) based on the point of thermal degradation, which is generally referred to as the onset temperature of decomposition $\left(\mathrm{T}_{\text {onset }}\right)$, to depict short-term stability. ${ }^{14}$ These direct measurements estimate the degradation behavior of the compounds. Del Sesto et al. ${ }^{15}$ reported that ILs, such as $\left[\mathrm{C}_{4} \mathrm{mim}\right]\left[\mathrm{NTf}_{2}\right]$, begin degrading at temperatures of about $423 \mathrm{~K}$ despite the IL presenting a high $\mathrm{T}_{\text {onset }}$ of $728 \mathrm{~K}$. The biggest issue of TGA is that the values change with the heating rate set and frequently overestimate thermal stability. ${ }^{14}$

Isothermal and non-isothermal TGA measurements were applied to investigate IL thermal decomposition. The 
isothermal methods provide kinetic parameters determined for a specific temperature range and do not correspond to the entire thermal event. ${ }^{16,17}$ Therefore, to fully investigate, non-isothermal methods are applied to obtain kinetic parameters in all decomposition ranges of the compounds (e.g., 303 to $973 \mathrm{~K}$ ) by using multiple TGA runs of the sample. ${ }^{18,19}$

In this sense, the main goal of this study was to observe the thermal behavior of several imidazolium-based monoand dicationic ILs with longer alkyl chains by two distinct non-isothermal methods (Friedman and Ozawa-WallFlynn methods). ${ }^{20}$ Information about activation parameters of IL decomposition reactions such as enthalpy $\left(\Delta \mathrm{H}^{*}\right)$, entropy $\left(\Delta \mathrm{S}^{\ddagger}\right)$, and free Gibbs energy $\left(\Delta \mathrm{G}^{\ddagger}\right)$ were acquired by these methods. Thermal transitions of the ILs were also investigated. The IL used in the study is depicted in Figure 1.

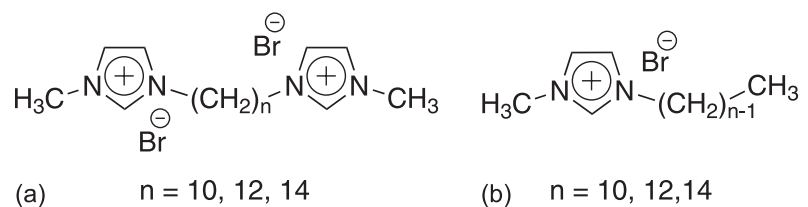

Figure 1. Structure of (a) monocationic and (b) dicationic ILs used in the study.

\section{Experimental}

\section{Materials}

1,10-Dibromodecane, 1,12-dibromododecane, 1,14-dibromotetradecane, 1-bromodecane, 1-bromododecane, 1-bromotetradecane, and 1-methylimidazole were purchased from Sigma-Aldrich (St. Louis, MO, USA). Acetonitrile and ethyl ether (HPLC) were purchased from Tedia (Rio de Janeiro, RJ, Brazil). All chemical products were of high-grade purity and used without further purification.

\section{Synthesis}

The ILs were synthesized in accordance with methodologies previously described in the literature..$^{21,22}$ The structures of all products were confirmed by nuclear magnetic resonance (NMR), mass spectra, and thermal analysis using differential scanning calorimetry (DSC). The IL water content was determined by Karl Fisher titration (Titrando 836, Metrohm, São Paulo, Brazil) and below $5 \%$ in all ILs.

\section{Thermal analysis}

Thermogravimetric analysis was carried out on a TGA
Q5000 (TA Instruments Inc., USA). The heating rates were $275.15,276.15,278.15,280.15$, and $283.15 \mathrm{~K} \mathrm{~min}^{-1}$. The $\mathrm{N}_{2}$ flow rate was $25 \mathrm{~mL} \mathrm{~min}{ }^{-1}$ and temperature ranged from 298.15 to $973.15 \mathrm{~K}$. Sample mass was $2-5 \mathrm{mg}$. The TGA equipment was calibrated by $\mathrm{CaC}_{2} \mathrm{O}_{4} \cdot \mathrm{H}_{2} \mathrm{O}$ (99.9\%). Modulated differential scanning calorimetry (MDSC) experiments were performed using an MDSC Q2000 (T-zero ${ }^{\mathrm{TM}}$ DSC technology, TA Instruments Inc., New Castle, DE, USA). A mechanical cooling system was used for experimental measurements. Dry, high purity $(99.999 \%)$ nitrogen gas was used as the purge gas $\left(50 \mathrm{~mL} \mathrm{~min}{ }^{-1}\right)$. The instrument was initially calibrated in the standard MDSC mode using the extrapolated onset temperatures of melting indium $(429.75 \mathrm{~K})$ at a heating rate of $283.15 \mathrm{~K} \mathrm{~min}^{-1}$. Heating capacity calibration was done by running a standard sapphire $\left(\alpha-\mathrm{Al}_{2} \mathrm{O}_{3}\right)$ measurement at the experimental temperature. The heating rate used for the samples was $283.15 \mathrm{~min}^{-1}$. The sample masses were weighed on a Sartorius M 500 P for an accuracy of $\pm 0.001 \mathrm{mg}$ and crimped in hermetic aluminum pans with lids. The masses of the reference and sample pans with lids were measured $(51 \pm 0.02 \mathrm{mg})$.

\section{Results and Discussion}

The decomposition profile and correlated data were first carried out using a TGA measurement at a heating rate of $283.15 \mathrm{~min}^{-1}$ for each ionic liquid. Onset decomposition temperature $\left(\mathrm{T}_{\text {onset }}\right)$, final decomposition temperature $\left(\mathrm{T}_{\mathrm{f}}\right)$, decomposition percentage $(\%)$, and maximum decomposition temperature $\left(\mathrm{T}_{\mathrm{d}}\right)$ are shown in Table 1. The decomposition percentage indicates that IL decomposition is almost complete (> 94\%) in the evaluated temperature range. The $\mathrm{T}_{\text {onset }}$ shows that no thermal degradation, based on mass loss, occurs at temperatures below $528 \mathrm{~K}$. On the other hand, $\mathrm{T}_{\mathrm{f}}$ indicates the temperature at which mass loss is complete. The $\mathrm{T}_{\mathrm{d}}$ of the ILs ranged from 560 to $590 \mathrm{~K}$ and corresponds to the peak temperature in the derivative weight $(\%)$ as a function of temperature (T) in the TGA thermogram (Figure 2).

Decomposition kinetic studies were performed to determine the influence of structural parameters, such as an additional cationic head and alkyl chain length in the thermal degradation process of ILs. The decomposition profile of [BisDec(MIM) $\left.)_{2}\right][\mathrm{Br}]$ at heating rates of 275.15, $276.15,278.15,280.15$, and $283.15 \mathrm{~K} \mathrm{~min}^{-1}$ is shown in Figure 2. The decomposition profiles of other ILs are depicted in the Supplementary Information (SI) section. The TGA curves of $\left[\mathrm{BisDec}(\mathrm{MIM})_{2}\right][\mathrm{Br}]$ show endothermic behavior with apparently no mass loss until $500 \mathrm{~K}$, presenting a single-step mass loss. 
Table 1. Thermogravimetric data obtained by TGA at a heating rate of $283.15 \mathrm{~K} \mathrm{~min}^{-1}$

\begin{tabular}{lcccc}
\hline IL & $\mathrm{T}_{\text {onset }} / \mathrm{K}$ & $\mathrm{T}_{\mathrm{f}}^{\mathrm{d}} / \mathrm{K}$ & Decomposition percentage $/ \%$ & $\mathrm{~T}_{\mathrm{d}}^{\mathrm{e}} / \mathrm{K}$ \\
\hline$[\operatorname{Dec}(\mathrm{MIM})][\mathrm{Br}]^{\mathrm{a}}$ & 538 & 694 & 98 & 571 \\
{$[\operatorname{DoDec}(\mathrm{MIM})][\mathrm{Br}]^{\mathrm{a}}$} & 530 & 648 & 95 & 565 \\
{$[\operatorname{TetDec}(\mathrm{MIM})][\mathrm{Br}]^{\mathrm{a}}$} & 528 & 611 & 95 & 560 \\
{$\left[\operatorname{BisDec}(\mathrm{MIM})_{2}\right][2 \mathrm{Br}]^{\mathrm{b}}$} & 572 & 667 & 97 & 590 \\
{$\left[\operatorname{BisDoDec}(\mathrm{MIM})_{2}\right][2 \mathrm{Br}]^{\mathrm{b}}$} & 562 & 742 & 97 & 582 \\
{$\left[\operatorname{BisTetDec}(\mathrm{MIM})_{2}\right][2 \mathrm{Br}]^{\mathrm{b}}$} & 567 & 747 & 94 & 588 \\
\hline
\end{tabular}

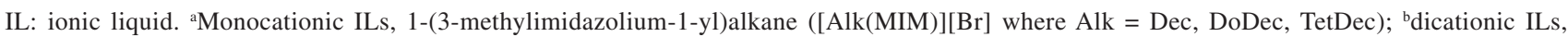
1,n-bis(3-methylimidazolium-1-yl)alkane ([BisAlk(MIM) $]$ ] 2 2Br $]$, where Alk = Dec, DoDec, TetDec) (Dec = decane; DoDec = dodecane; TetDec = tetradecane); conset decomposition temperature; ${ }^{\mathrm{d} f i n a l}$ decomposition temperature; ${ }^{\mathrm{e}}$ temperature of sample maximum decomposition.

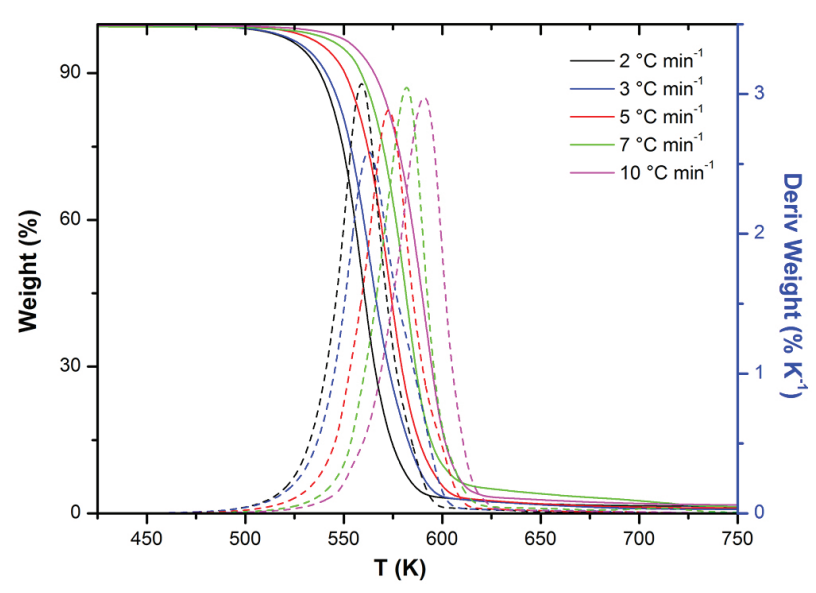

Figure 2. Overlap of TGA thermograms for $\left[\mathrm{Bis} \operatorname{Dec}(\mathrm{MIM})_{2}\right][2 \mathrm{Br}]$ at different heating rates.

From the TGA data, two different methodologies were applied to analyze the decomposition kinetics of the ILs, the Ozawa-Wall-Flynn (O-W-F) and Friedman methodologies. Both methods allow kinetic parameters to be determined from the non-isothermal thermogravimetric data at different heating rates. The weight loss variation observed in the TGA analysis is the mass fraction of conversion $(\alpha)$ and given by equation $1 .{ }^{23}$

$\alpha=\frac{\mathrm{m}_{0}-\mathrm{m}_{\mathrm{t}}}{\mathrm{m}_{0}-\mathrm{m}_{\mathrm{f}}}$

where $m_{0}$ is the initial mass, $m_{f}$ is the final mass, and $m_{t}$ is the mass in the time t. The kinetic results of Ea and $\ln \mathrm{A}$ were obtained using the Ozawa-Wall-Flynn (O-W-F) and Friedman methods by applying equations 2 and 3 to the experimental data, respectively. ${ }^{23}$

$$
\begin{aligned}
& \ln \beta=\ln \left[\mathrm{A} \frac{\mathrm{f}(\alpha)}{\mathrm{d} \alpha / \mathrm{dT}}\right]-\frac{\mathrm{E}_{\mathrm{a}}}{\mathrm{RT}} \\
& \ln \left(\beta \frac{\mathrm{d} \alpha}{\mathrm{dT}}\right)=\ln [\operatorname{Af}(\alpha)]-\frac{\mathrm{E}_{\mathrm{a}}}{\mathrm{RT}}
\end{aligned}
$$

In equations 2 and $3, \beta$ is the heating rate, $\mathrm{A}$ is the collision factor and represents the total number of collisions between molecules, Ea is the activation energy necessary to break one mole of bonds between the atoms of the molecules, $\mathrm{T}$ is the absolute temperature, and $\mathrm{R}$ is the constant of ideal gases. The linear fitting of $\ln \beta v s$. 1/T furnishes Ea and $\ln \mathrm{A}$ in each $\alpha$ evaluated by the O-W-F method. The Friedman method allowed these kinetic parameter to be determined by linear fitting of the curves $\ln$ $(\beta \mathrm{d} \alpha / \mathrm{dt}$ ) as a function of $1 / \mathrm{T}$ (equation 3$) .{ }^{23}$ The application of the O-W-F and Friedman methods for [BisDec $(\mathrm{MIM})_{2}$ ] $[2 \mathrm{Br}]$ and $[\mathrm{Dec}(\mathrm{MIM})][\mathrm{Br}]$, respectively, are presented in Figures 3 and 4.

The angular coefficient of the linear fragments in each $\alpha$ of both methods provides the energy activation value (Ea) of the decomposition process in each $\alpha$. The collision factor (A) can be estimated from the linear coefficient values. ${ }^{23}$ The results of $\mathrm{Ea}$ and $\ln \mathrm{A}$ as a function of $\alpha$ of $\left[\mathrm{BisDec}(\mathrm{MIM})_{2}\right][2 \mathrm{Br}]$ and $[\mathrm{Dec}(\mathrm{MIM})][\mathrm{Br}]$ are depicted in Figures 5 and 6, respectively.

The Ea and ln A of both, [BisDec(MIM) $\left.)_{2}\right][2 \mathrm{Br}]$ and [Dec(MIM)][Br], change as a function of mass fraction of conversion $(\alpha)$ by the O-W-F method. This indicates that the decomposition reaction of this IL as a function of temperature occurs in multiple steps with different activation energy values (Figures $5 \mathrm{a}$ and $6 \mathrm{a}$ ). The same tendency was observed for Ea and $\ln \mathrm{A} v s . \alpha$ obtained by the Friedman method (Figures $5 b$ and $6 b$ ).

As previously reported,,${ }^{14}$ in ILs based on the imidazolium ring, the biggest component of thermal degradation is neutralization of the imidazolium ring. This reaction occurs through a second order nucleophilic substitution $\left(\mathrm{S}_{\mathrm{N}} 2\right)$, promoting loss of the IL alkyl chain. However, additional and simultaneous bond breaks can occur in these ILs and may explain the different Ea and $\ln \mathrm{A}$ values observed as $\alpha$ increased. The kinetic energy of the system increases as the temperature increases and the Ea of further thermal degradation reactions can be reached. This process leads to 

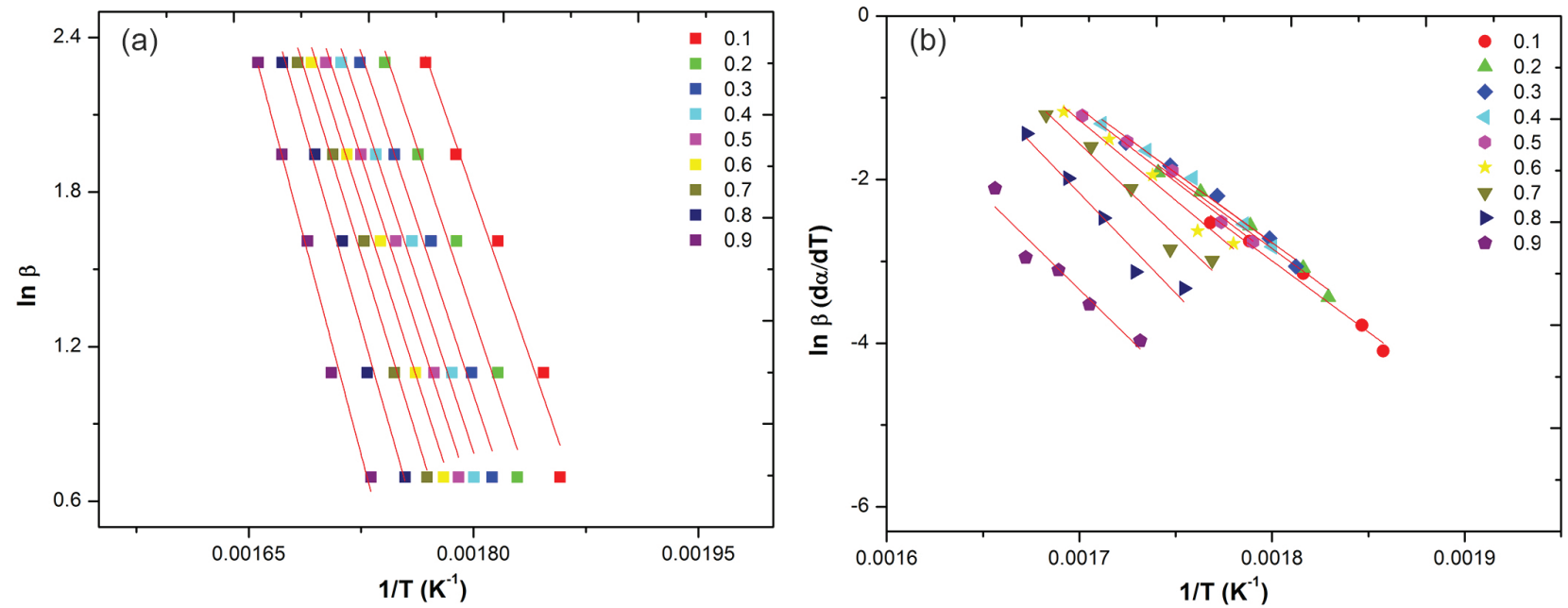

Figure 3. Curves of $\ln \beta$ vs. 1/T (a) and $\ln \beta$ (d $\alpha / \mathrm{dT})$ vs. 1/T (b) for [BisDec(MIM) 2 [2Br]. Values of $\alpha$ are represented as: 0.1 red; 0.2 green; 0.3 blue; 0.4 cyan; 0.5 magenta; 0.6 yellow; 0.7 olive; 0.8 navy blue; 0.9 purple.
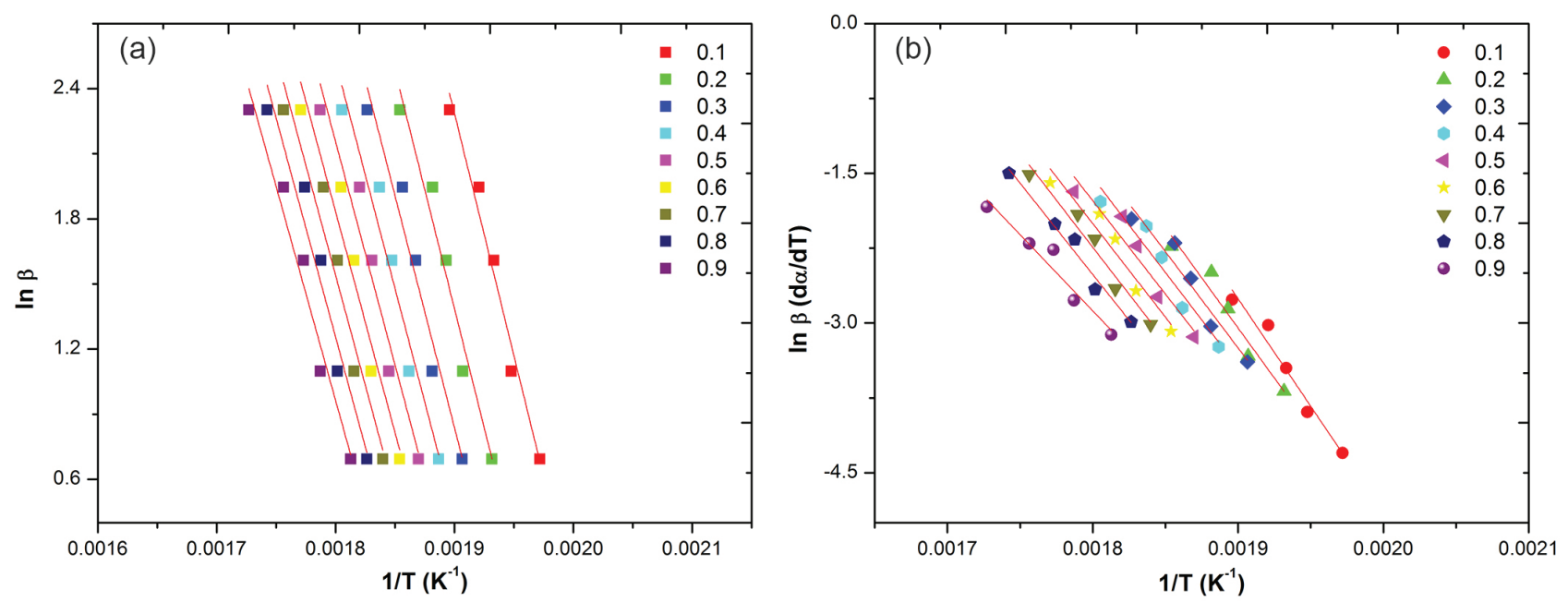

Figure 4. Curves of $\ln \beta$ vs. 1/T (a) and $\ln \beta$ (d $\alpha / \mathrm{dT}$ ) vs. 1/T (b) for [Dec(MIM)][Br]. Values of $\alpha$ are represented in colors: 0.1 red; 0.2 green; 0.3 blue; 0.4 cyan; 0.5 magenta; 0.6 yellow; 0.7 olive; 0.8 navy blue; 0.9 purple.
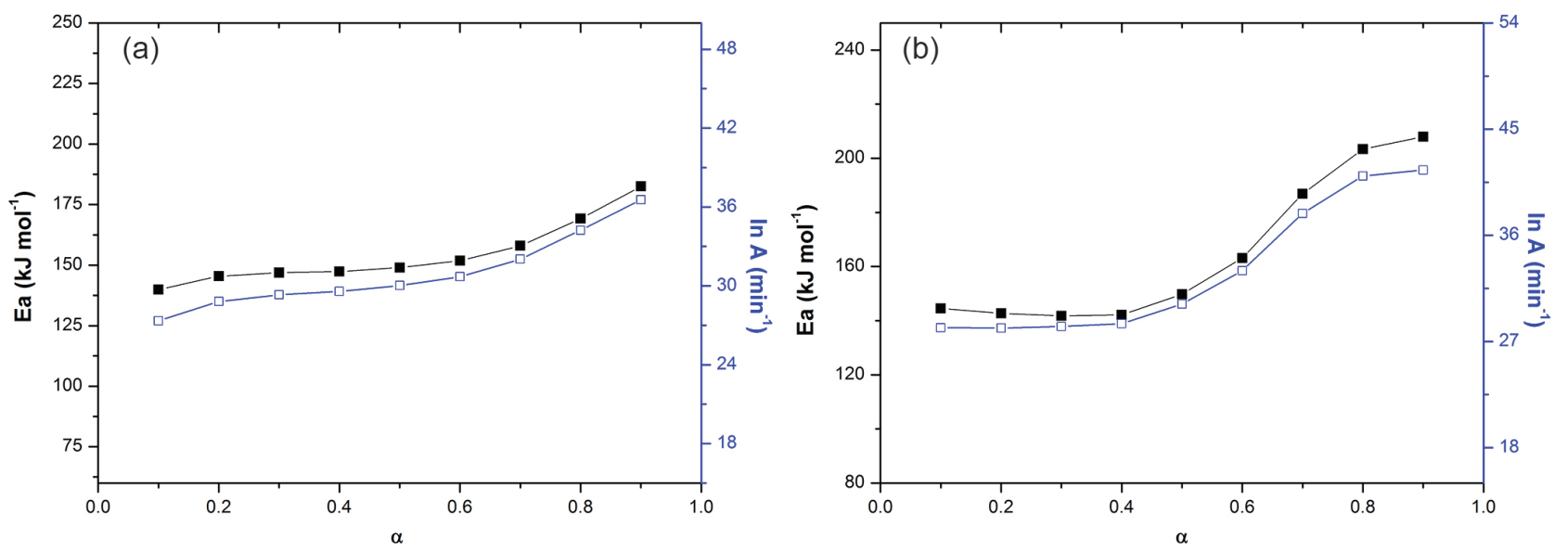

Figure 5. Curves of $\alpha$ vs. Ea and ln A for [BisDec(MIM) $\left.)_{2}\right][2 \mathrm{Br}]$ obtained by the O-W-F (a) and Friedman methods (b). 

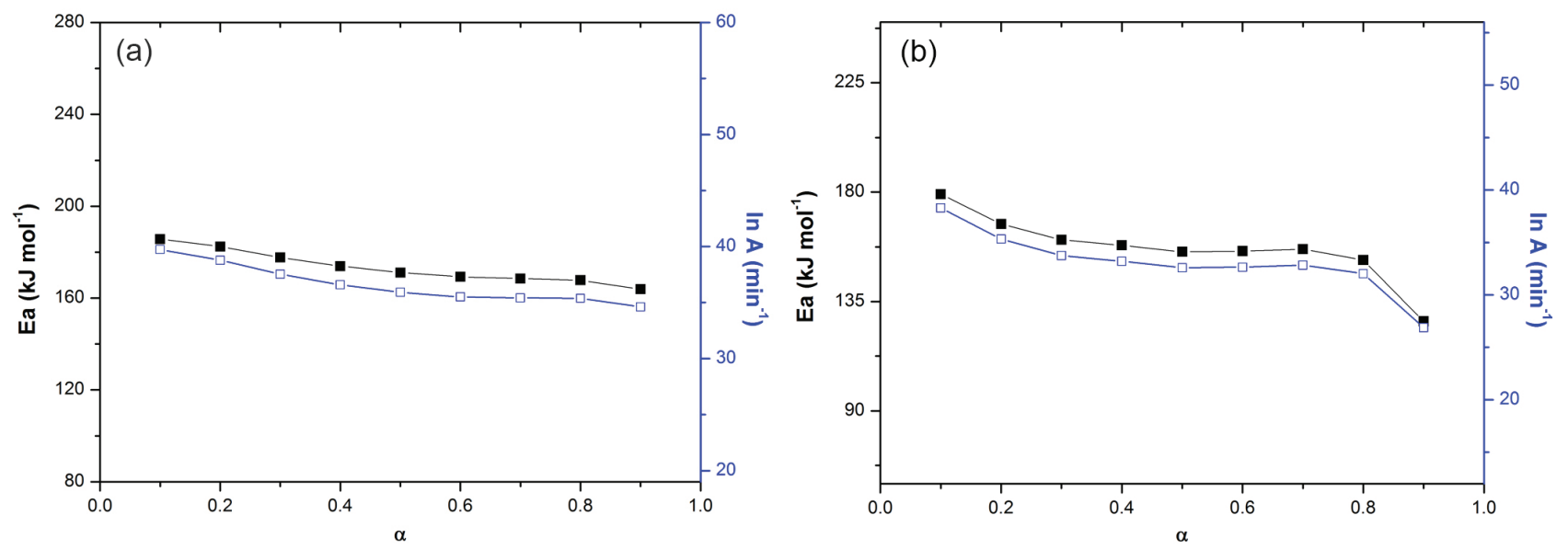

Figure 6. Curves of $\alpha v s$. Ea and ln A for [Dec(MIM)][Br] obtained by the O-W-F (a) and Friedman methods (b).

bond break reactions pattern according to the IL structure. For $\left[\mathrm{BisDec}(\mathrm{MIM})_{2}\right][2 \mathrm{Br}]$, the Ea and ln A increased as $\alpha$ increased, while for [Dec(MIM)][Br], the values of these parameters decreased. This distinction may be due to: (i) distinct decomposition reactions in the alkyl chain of mono- and dicationic ILs and (ii) decomposition of an additional imidazolium ring in dicationic ILs compared to their analogues monocationic ILs. These diverse behaviors were also observed for monocationic and dicationic ILs with different alkyl chain lengths $(\mathrm{n}=10,12$, and 14). In these cases, side reactions occur during the decomposition process. These reactions have competitive reaction pathways with different reaction rates dependent on temperature and heating rates. The results can be observed in the Supplementary Information (SI) section (Figures S6-S13 and Tables S1, S2). In general, the Ea and $\ln \mathrm{A}$ observed by the Friedman and O-W-F method have the same behavior as a function of $\alpha$. It is important to consider that both methods $(\mathrm{O}-\mathrm{W}-\mathrm{F}$ and Friedman) are distinct. The Ea and ln A from Ozawa is obtained from $\ln \beta v$ s. 1/T plot, while ln ( $\beta \mathrm{d} \alpha / \mathrm{dt})$ curve as a function of $1 / \mathrm{T}$ is used in the Friedman method. The decomposition kinetics of monocationic IL [Oct(MIM)] [Br] was previously estimated in the literature by Arellano et al. ${ }^{24}$ in which Ea and $\ln \mathrm{A}$ values found for the $533-573 \mathrm{~K}$ temperature range were $219.89 \mathrm{~kJ} \mathrm{~mol}^{-1}$ and $48.19 \mathrm{~min}^{-1}$, respectively. Previously, our research group observed values of $230.27 \mathrm{~kJ} \mathrm{~mol}^{-1}$ and $39.38 \mathrm{~min}^{-1}$ for Ea and $\ln \mathrm{A}$, respectively, for the same IL and temperature range $(\alpha=0.5)$. Considering that different methods were used, the values showed good agreement. ${ }^{25}$ Additionally, it is more important to consider that both Ea and $\ln \mathrm{A}$, from either methods, give the same tendency as a function of $\alpha$ for different ILs evaluated. The difference in the profile of Ea as a function of $\alpha$, which was observed for monoand dicationic ILs series, demonstrates that both alkyl chain lengths and additional imidazolium rings in the IL structures promote changes in IL thermal degradation. Thus, the degradation process rate constant $(\mathrm{k})$ may be obtained as a function of $\alpha$ by applying Arrhenius' equation in the Ea and $\ln \mathrm{A}$. The profile of Ea and $\mathrm{k}$ of each IL vs. $\alpha$ demonstrates differences as $\alpha$ increased. The results are shown in Figures 7 and 8 for monocationic and dicationic ILs, respectively.

The Ea values demonstrate the energy difference between the reactants and reaction transition state. The greater the Ea value, the more energy is required for the reactants to reach the transition state of the decomposition reaction. From the profile of $\mathrm{Ea}$ as a function of $\alpha$, the stability order can be attributed to mono- and dicationic ILs. For monocationic, the order [Dec(MIM)][Br] > $[$ TetDec(MIM)][Br] > [DoDec(MIM)][Br] was found (Figure 7a). For dicationic, the order $\left[\mathrm{BisDoDec}(\mathrm{MIM})_{2}\right][2 \mathrm{Br}]>\left[\mathrm{BisTetDec}(\mathrm{MIM})_{2}\right][2 \mathrm{Br}]>$ $\left[\mathrm{BisDec}(\mathrm{MIM})_{2}\right][2 \mathrm{Br}]$ was found (Figure $8 \mathrm{a}$ ). These orders are maintained in all $\alpha$ evaluated. These results indicate that the stability order have no linear relation with the alkyl chain length. Arellano et al. ${ }^{24}$ determined the thermal stability of [But(MIM)]Br and [Oct(MIM)]Br through isothermal TG experiments. The results indicated higher thermal stability of [Oct(MIM)]Br with longer alkyl chains based on a higher activation energy in the range of 533-573 K compared to [But(MIM)]Br with shorter alkyl chain. Khan et al. ${ }^{26}$ determined Ea and A of 1-propyronitrile imidazolium trifluoroacetate ionic liquid by the O-W-F method. The high value of $\mathrm{Ea}\left(173 \mathrm{~kJ} \mathrm{~mol}^{-1}\right)$ indicated that this IL is suitable to be used for cellulose dissolution and other industrial applications. In this sense, Hao et al.$^{17}$ found $\mathrm{Ea}$ and $\mathrm{A}$ of $125 \mathrm{~kJ} \mathrm{~mol}^{-1}$ and $3.0 \times 10^{13}$, respectively, for isothermal decomposition of 1-allyl-3-methylimidazolium chloride. Due to the high thermal stability, the authors reaffirm this IL as a powerful cellulose solvent at the 

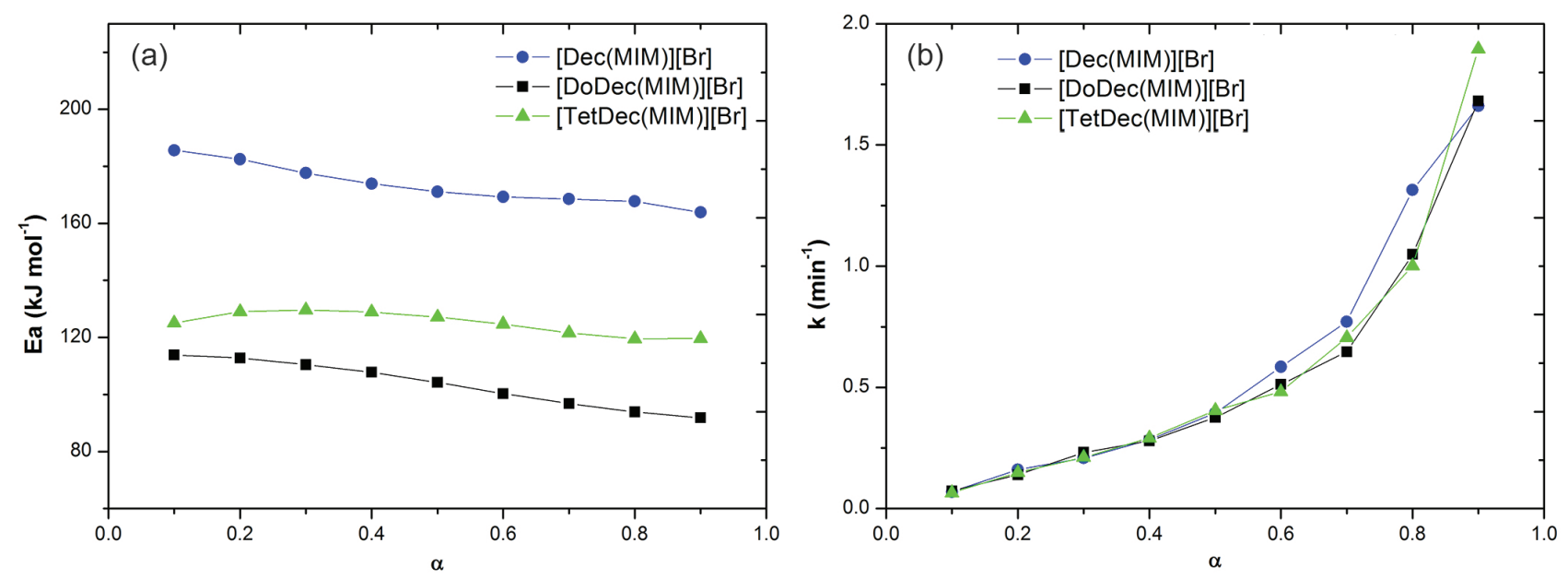

Figure 7. Relation between (a) Ea and (b) k vs. $\alpha$ for monocationic ILs by the O-W-F method.
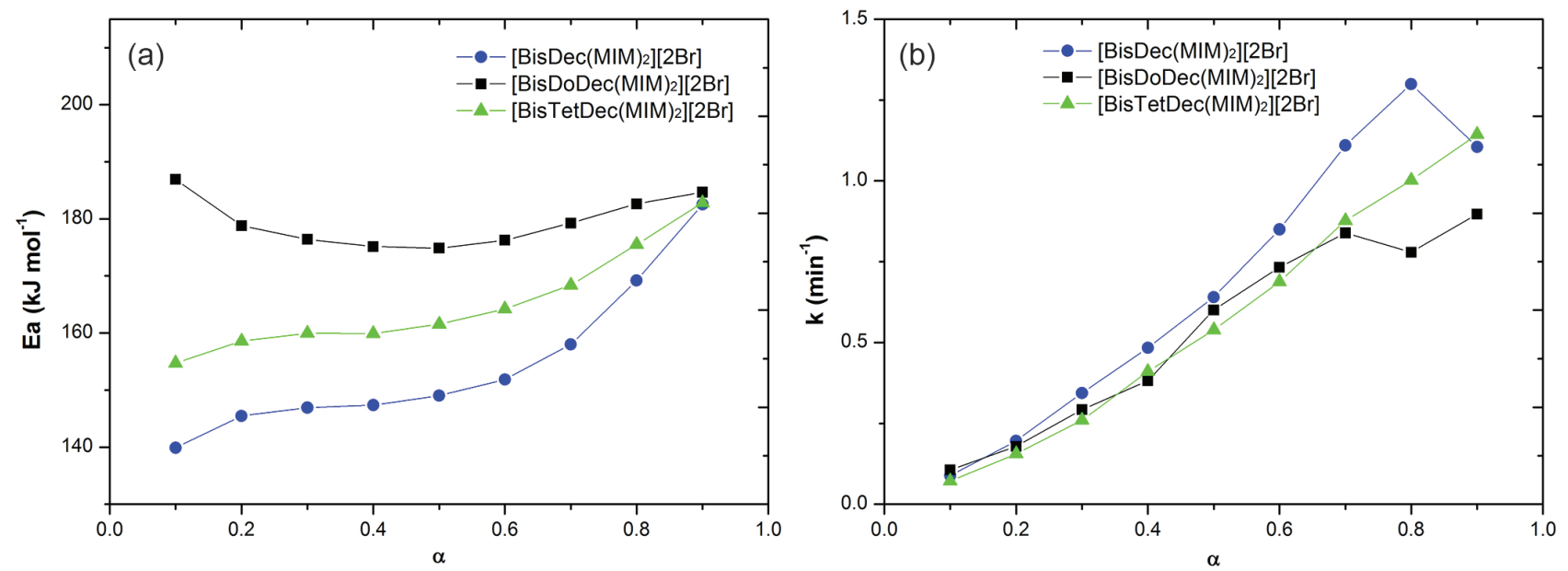

Figure 8. Relation between (a) Ea and (b) k vs. $\alpha$ for dicationic ILs by the O-W-F method.

operating temperature $(373 \mathrm{~K}) .{ }^{27}$ The degradation process rate constant $(\mathrm{k})$ of monocationic ILs increased significantly in $\alpha>0.5$ (Figure $7 \mathrm{~b}$ ). On the other hand, an almost linear increase of $\mathrm{k}$ as a function $\alpha$ for dicationic ILs was observed (Figure 8b). These data show the differences in the degradation process of these structures. The investigated kinetic parameters (Ea, $\mathrm{A}$ and $\mathrm{k}$ ) were used to evaluate the activation parameters of the ILs. These parameters of thermal decomposition of ILs were calculated at $298.15 \mathrm{~K}$ using Ea and $\ln \mathrm{A}$ values in $\alpha$ of 0.1 and 0.5 , were $\alpha=0.1$ and 0.5 corresponds to 10 and $50 \%$ of activity loss, respectively. The determination of these parameters in 10 and $50 \%$ of activity loss is important in a pharmaceutical point of view. The $10 \%$ of activity loss is generally associated to the shelf life of the compounds while $50 \%$ of activity loss is related with the half life of the compounds in pharmaceutical industries. The entropy $\left(\Delta \mathrm{S}^{\ddagger}\right)$, enthalpy $\left(\Delta \mathrm{H}^{\ddagger}\right)$ and Gibbs free energy $\left(\Delta \mathrm{G}^{\ddagger}\right)$ of activation were calculated using the following equations. ${ }^{28}$

$$
\begin{aligned}
& A \exp \frac{-E a}{R T}=v \exp \frac{-\Delta G^{\ddagger}}{R T} \\
& \Delta H^{\ddagger}=E a-R T \\
& \Delta G^{\ddagger}=\Delta H^{\ddagger}-T \Delta S^{\ddagger}
\end{aligned}
$$

In equations 4,5 and $6, v=\mathrm{k}_{\mathrm{B}} \mathrm{T} / \mathrm{h}$ (where $\mathrm{k}_{\mathrm{B}}$ is Boltzmann constant and $\mathrm{h}$ is Plank constant), $\mathrm{T}$ is the temperature in $\mathrm{K}$, and $\mathrm{R}$ is the gas constant in $\mathrm{kJ} \mathrm{mol}^{-1}$. The kinetics and activation data of monocationic and dicationic ILs were obtained in 10 and $50 \%$ of activity loss and are presented in Table 2.

From $E a$ and $\ln A$ data, the $\Delta \mathrm{G}^{\ddagger}$ is obtained by equation 4 in $\alpha=0.1$ and 0.5 . The $\Delta \mathrm{G}^{\ddagger}$ is influenced by enthalpy $\left(\Delta \mathrm{H}^{\ddagger}\right)$ and entropy $\left(\Delta \mathrm{S}^{\ddagger}\right)$ of the activated complex formation. As expected, the $\Delta \mathrm{G}^{\ddagger}$ and $\Delta \mathrm{H}^{\ddagger}$ values are positive due to the decomposition of ILs being endergonic and endothermic processes, respectively. These parameters show that the 
Table 2. Comparison of thermokinetics and activation parameters at $298.15 \mathrm{~K}$ for the greatest thermal degradation component of the ILs obtained by the O-W-F method

\begin{tabular}{|c|c|c|c|c|c|c|}
\hline IL & $\begin{array}{c}\mathrm{Ea} / \\
\left(\mathrm{kJ} \mathrm{mol}^{-1}\right)\end{array}$ & $\ln \mathrm{A} / \mathrm{s}^{-1}$ & $\begin{array}{c}\Delta \mathrm{G}^{\ddagger} / \\
\left.(\mathrm{kJ} \mathrm{mol})^{-1}\right)\end{array}$ & $\begin{array}{c}\Delta \mathrm{H}^{*} / \\
\left(\mathrm{kJ} \mathrm{mol}{ }^{-1}\right) \\
\end{array}$ & $\begin{array}{c}\Delta \mathrm{S}^{\ddagger} / \\
\left(\mathrm{kJ} \mathrm{mol}^{-1} \mathrm{~K}^{-1}\right) \\
\end{array}$ & $\begin{array}{r}-\mathrm{T} \Delta \mathrm{S}^{\ddagger} / \\
\left(\mathrm{kJ} \mathrm{mol}{ }^{-1}\right) \\
\end{array}$ \\
\hline$[\operatorname{Dec}(\mathrm{MIM})][\mathrm{Br}]^{\mathrm{a}}$ & $\begin{array}{l}186^{\mathrm{c}} \\
171^{\mathrm{d}}\end{array}$ & $\begin{array}{l}36^{\mathrm{c}} \\
32^{\mathrm{d}}\end{array}$ & $\begin{array}{l}170^{\mathrm{c}} \\
165^{\mathrm{d}}\end{array}$ & $\begin{array}{l}183^{\mathrm{c}} \\
169^{\mathrm{d}}\end{array}$ & $\begin{array}{l}0.0431^{\mathrm{c}} \\
0.0112^{\mathrm{d}}\end{array}$ & $\begin{array}{l}-12.9^{\mathrm{c}} \\
-3.4^{\mathrm{d}}\end{array}$ \\
\hline$[\operatorname{DoDec}(\mathrm{MIM})][\mathrm{Br}]^{\mathrm{a}}$ & $\begin{array}{l}114^{\mathrm{c}} \\
104^{\mathrm{d}}\end{array}$ & $\begin{array}{l}19^{\mathrm{c}} \\
18^{\mathrm{d}}\end{array}$ & $\begin{array}{l}139^{\mathrm{c}} \\
134^{\mathrm{d}}\end{array}$ & $\begin{array}{l}111^{\mathrm{c}} \\
102^{\mathrm{d}}\end{array}$ & $\begin{array}{l}-0.0916^{c} \\
-0.1067^{d}\end{array}$ & $\begin{array}{l}27.3^{\mathrm{c}} \\
31.8^{\mathrm{d}}\end{array}$ \\
\hline$[\operatorname{TetDec}(\mathrm{MIM})][\mathrm{Br}]^{\mathrm{a}}$ & $\begin{array}{l}125^{\mathrm{c}} \\
127^{\mathrm{d}}\end{array}$ & $\begin{array}{l}22^{\mathrm{c}} \\
23^{\mathrm{d}}\end{array}$ & $\begin{array}{l}144^{\mathrm{c}} \\
144^{\mathrm{d}}\end{array}$ & $\begin{array}{l}123^{\mathrm{c}} \\
125^{\mathrm{d}}\end{array}$ & $\begin{array}{l}-0.0711^{\mathrm{c}} \\
-0.0647^{\mathrm{d}}\end{array}$ & $\begin{array}{l}21.2^{\mathrm{c}} \\
19.3^{\mathrm{d}}\end{array}$ \\
\hline$\left[\operatorname{BisDec}(\mathrm{MIM})_{2}\right][2 \mathrm{Br}]^{\mathrm{b}}$ & $\begin{array}{l}140^{c} \\
149^{d}\end{array}$ & $\begin{array}{l}27^{\mathrm{c}} \\
30^{\mathrm{d}}\end{array}$ & $\begin{array}{l}155^{\mathrm{c}} \\
158^{\mathrm{d}}\end{array}$ & $\begin{array}{l}137^{\mathrm{c}} \\
147^{\mathrm{d}}\end{array}$ & $\begin{array}{l}-0.0599^{c} \\
-0.0376^{d}\end{array}$ & $\begin{array}{l}17.9^{\mathrm{c}} \\
11.2^{\mathrm{d}}\end{array}$ \\
\hline$\left[\operatorname{BisDoDec}(\mathrm{MIM})_{2}\right][2 \mathrm{Br}]^{\mathrm{b}}$ & $\begin{array}{l}187^{\mathrm{c}} \\
175^{\mathrm{d}}\end{array}$ & $\begin{array}{l}38^{\mathrm{c}} \\
36^{\mathrm{d}}\end{array}$ & $\begin{array}{l}176^{\mathrm{c}} \\
170^{\mathrm{d}}\end{array}$ & $\begin{array}{l}184^{\mathrm{c}} \\
172^{\mathrm{d}}\end{array}$ & $\begin{array}{l}0.0286^{\mathrm{c}} \\
0.0092^{\mathrm{d}}\end{array}$ & $\begin{array}{l}-8.5^{\mathrm{c}} \\
-2.8^{\mathrm{d}}\end{array}$ \\
\hline$\left[\operatorname{BisTetDec}(\mathrm{MIM})_{2}\right][2 \mathrm{Br}]^{\mathrm{b}}$ & $\begin{array}{l}155^{\mathrm{c}} \\
162^{\mathrm{d}}\end{array}$ & $\begin{array}{l}31^{\mathrm{c}} \\
33^{\mathrm{d}}\end{array}$ & $\begin{array}{l}162^{\mathrm{c}} \\
164^{\mathrm{d}}\end{array}$ & $\begin{array}{l}152^{\mathrm{c}} \\
159^{\mathrm{d}}\end{array}$ & $\begin{array}{l}-0.0322^{\mathrm{c}} \\
-0.0161^{\mathrm{d}}\end{array}$ & $\begin{array}{l}9.6^{\mathrm{c}} \\
4.8^{\mathrm{d}}\end{array}$ \\
\hline
\end{tabular}

IL: ionic liquid. ${ }^{a}$ Monocationic ILs, 1-(3-methylimidazolium-1-yl)alkane ([Alk(MIM)][Br] where Alk = Dec, DoDec, TetDec); ${ }^{b}$ dicationic ILs, 1,n-bis(3-methylimidazolium-1-yl)alkane $\left(\left[\operatorname{BisAlk}(\mathrm{MIM})_{2}\right][2 \mathrm{Br}]\right.$, where Alk = Dec, DoDec, TetDec $)($ Dec $=$ decane; DoDec = dodecane; TetDec $=$ tetradecane); ${ }^{\mathrm{c}} 10 \%$ of activity loss; ${ }^{\mathrm{d}} 50 \%$ of activity loss.

decomposition reactions of the ILs are non-spontaneous and heat dependent. The greater and more positive the $\Delta \mathrm{H}^{\ddagger}$ values, the more energy is necessary to break covalent bonds of ILs. This value shows the energy necessary for the initial IL structure to reach the activated complex, and the values are similar to the kinetic parameter Ea. In general, the $\Delta \mathrm{H}^{\ddagger}$ followed the same tendency of $\Delta \mathrm{G}^{\ddagger}$ data. The $\Delta \mathrm{H}^{\ddagger}$ values confirm the stability order estimated based on Ea values for mono- and dicationic ILs. Based on these values, the relative stability order can be placed as: $\left[\mathrm{BisDoDec}(\mathrm{MIM})_{2}\right][2 \mathrm{Br}]>[\operatorname{Dec}(\mathrm{MIM})][\mathrm{Br}]>$ $\left[\operatorname{BisTetDec}(\mathrm{MIM})_{2}\right][2 \mathrm{Br}]>\left[\mathrm{BisDec}(\mathrm{MIM})_{2}\right][2 \mathrm{Br}]>$ $[$ TetDec(MIM) $][\mathrm{Br}]>[\operatorname{DoDec}(\mathrm{MIM})][\mathrm{Br}]$. The dicationic IL [BisDoDec $\left.(\mathrm{MIM})_{2}\right][2 \mathrm{Br}]$ is the structure more thermodynamically stable. In general, the dicationic ILs are more stable than monocationic ILs with the exception of [Dec(MIM)][Br].

Entropy $\left(\Delta S^{\ddagger}\right)$ is a measurement of the degree of order produced or lost when comparing the transition state with the reactants. Low activation entropy values indicate that the compounds have low reactivity and require more time to reach the activated complex. ${ }^{28}$ Thus, the lower $\Delta \mathrm{S}^{*}$ values for these ILs systems confirm that its activated complex in decomposition process possesses a higher arrangement degree. The $\Delta \mathrm{S}^{\ddagger}$ of ILs decomposition reactions was negative, except for [Dec(MIM)][Br] and $\left[\mathrm{BisDoDec}(\mathrm{MIM})_{2}\right][2 \mathrm{Br}]$. In these two ILs, the evaluated $\alpha$ demonstrated low positive entropy values. These results are attributed to the high values of Ea and $\ln \mathrm{A}$, which were obtained by experimental data. The positive $\Delta \mathrm{S}^{\ddagger}$ observed for these structures may be the result of a significant amount of bond cleavage occurring in the transition state..$^{29}$ Furthermore, the mechanism of thermal ionic liquid degradation is likely complex because of the multiple parameters that must be considered. The decomposition mechanisms may be subjected to multiple simultaneous reactions, autocatalytic effects, and competing reaction pathways with different reaction rates dependent on temperature and heating rates. ${ }^{14,30}$ The kinetics and activation parameters of monocationic and dicationic ILs as function of the number of carbons (nC) are shown in Figure 9.

Dicationic ILs present increased values of Ea and $\ln A$, when $n=12$ carbons, while values for the monocationic ILs decreased (Figure 9a). This behavior is also observed in $\Delta \mathrm{G}^{\ddagger}$ and $\Delta \mathrm{H}^{\ddagger}$ parameters (Figure $9 \mathrm{~b}$ ). On the other hand, the $T \Delta S^{\ddagger}$ term of the Gibbs free energy equation increased for monocationic IL and decreased for dicationic when the IL alkyl chain was composed of 12 carbons. These observations reinforce that the alkyl chain length influenced both ILs series evaluated, although not linearly.

Figures $10 \mathrm{a}$ and $10 \mathrm{~b}$ demonstrate the $\ln \mathrm{k} v s .1 / \mathrm{T}$ for 10 and $50 \%$ of activity loss, respectively. As observed, the first order of reaction kinetics, for both mono- and dicationic IL degradation, follows Arrhenius rate law. The straight lines demonstrate the same tendency in both 10 and $50 \%$ of activity loss. Nevertheless, in $50 \%$ of weight loss, the straight lines of $\left[\mathrm{BisDec}(\mathrm{MIM})_{2}\right][2 \mathrm{Br}]$, $\left[\mathrm{BisDoDec}(\mathrm{MIM})_{2}\right][2 \mathrm{Br}]$, [BisTetDec(MIM) $\left.)_{2}\right][2 \mathrm{Br}]$, and [Dec(MIM)][Br] became closer, while for [DoDec(MIM)] $[\mathrm{Br}]$ and $[\mathrm{TetDec}(\mathrm{MIM})][\mathrm{Br}]$ they were separated.

Monocationic ILs imidazolium-based present a transition phase from solid crystalline to smectic and a transition phase from smectic to an isotropic state when subjected to heating cycles in DSC. The smectic mesophase is characterized by having positional and orientational 

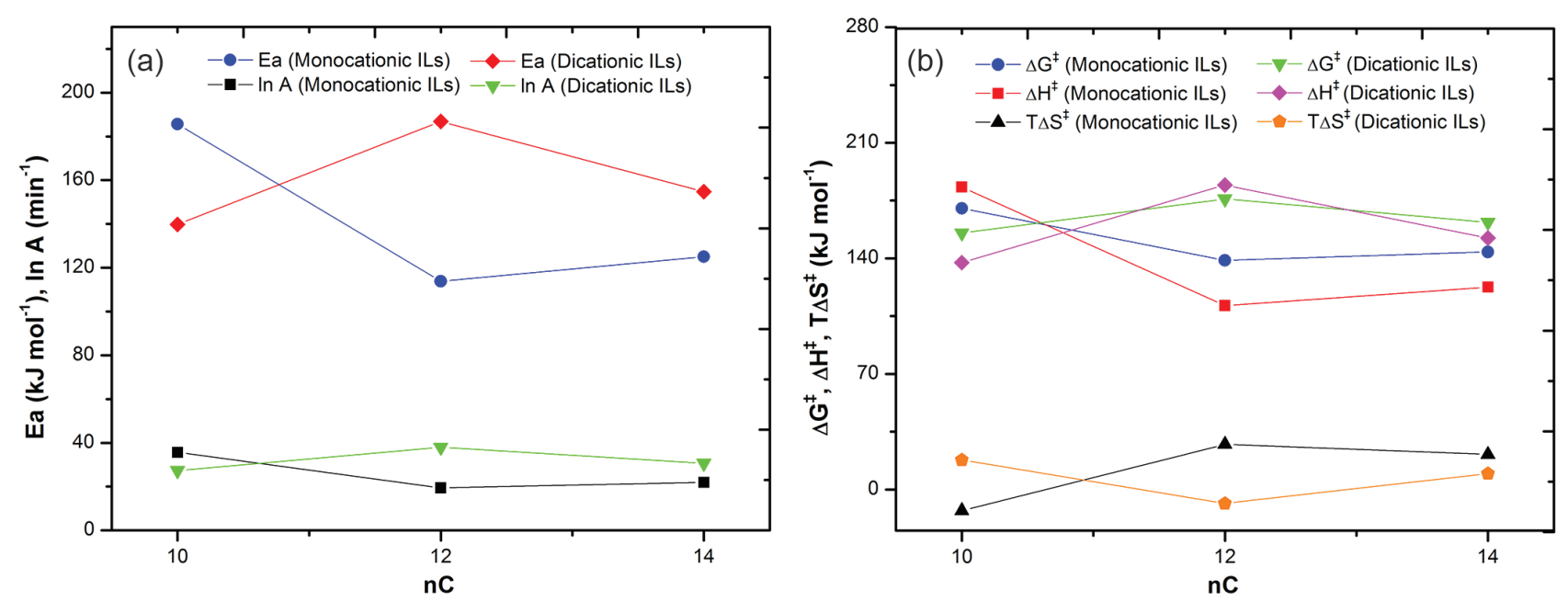

Figure 9. (a) Kinetics and (b) activation parameters as a function of the number of carbons (nC) of the IL alkyl chain in $10 \%$ of mass loss.
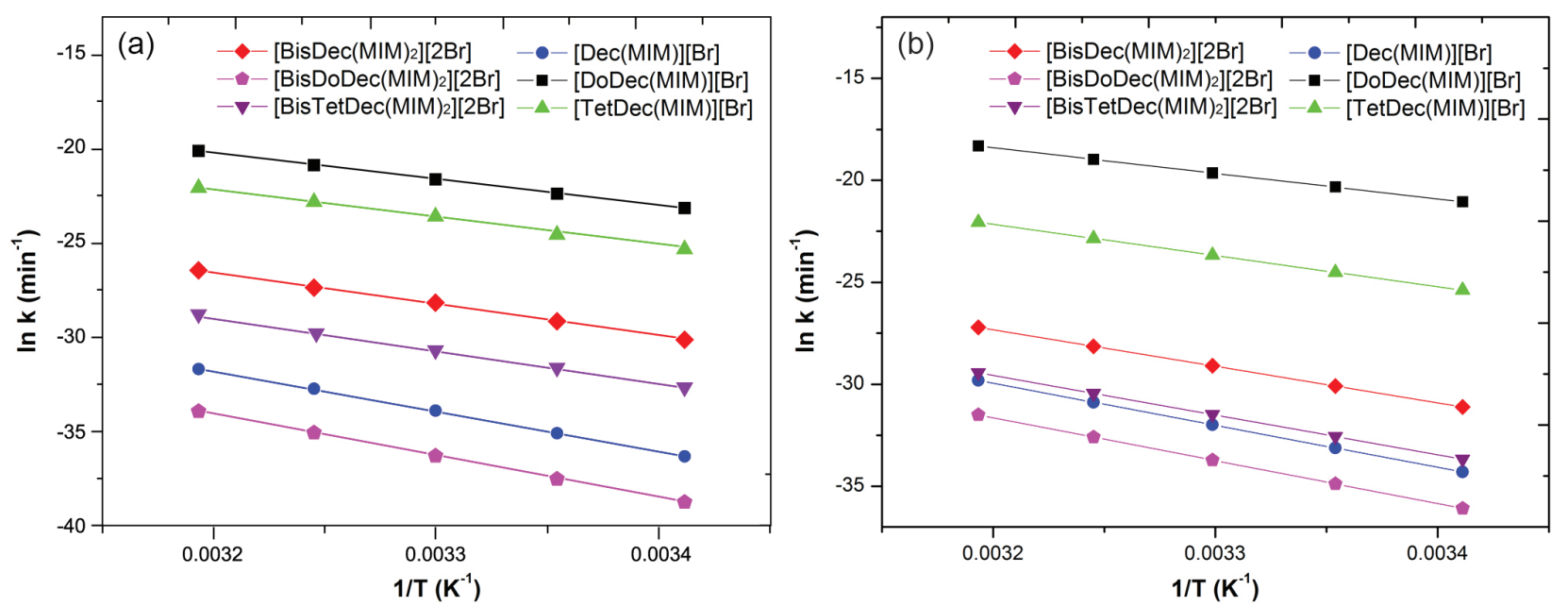

Figure 10. Relation between $\ln \mathrm{k} v s .1 / \mathrm{T}$ in (a) 10 and (b) $50 \%$ of activity loss for dicationic IL by the O-W-F method.

order and lower fluidity, which is arranged in layers. In the isotropic state, there is no positional and orientational ordering, therefore the molecules are randomly arranged in space. ${ }^{22,23}$

Thus, the mono- and dicationic ILs series were submitted to DSC to evaluate the phase transition. The first and second order thermal transitions obtained during the heating cycles for ILs are shown in Table 3.

In the first heating cycle, [Dec(MIM)][Br] melted and in the second heating cycle a glass transition $\left(\mathrm{T}_{\mathrm{g}}\right)$ was observed, indicating that this IL is crystalline and became amorphous after heating. These results are in agreement with Zhu et al., ${ }^{31}$ who showed that [DoDec(MIM)][Br] presents two reversible phase transitions during the first heating cycle (Figure 11, blue line). The first one concerns the crystalline solid transition into a smectic liquid $(\mathrm{S} \rightarrow \mathrm{SL})$ at $313 \mathrm{~K}$, with a $\Delta \mathrm{H}^{\circ}=39 \mathrm{~kJ} \mathrm{~mol}^{-1}$, and the second from a smectic liquid into an isotropic liquid $(\mathrm{SL} \rightarrow \mathrm{LI})$ at $397 \mathrm{~K}$, with a
$\Delta \mathrm{H}^{\circ}=0.56 \mathrm{~kJ} \mathrm{~mol}^{-1}$. The reverse transitions of these two thermal effects are shown in the cooling curves (Figure 11). In the second heating cycle, a shift of these transitions can be observed (Figure 11, red line). The crystalline solid transition to the smectic liquid ( $\mathrm{S} \rightarrow \mathrm{SL}$ ) occurs at $274 \mathrm{~K}$ $\left(\Delta \mathrm{H}=11 \mathrm{~kJ} \mathrm{~mol}^{-1}\right)$ and the transition from smectic liquid to isotropic liquid ( $\mathrm{SL} \rightarrow \mathrm{LI}$ ) occurs at $369 \mathrm{~K}\left(\Delta \mathrm{H}=0.6 \mathrm{~kJ} \mathrm{~mol}^{-1}\right)$. These results are in agreement with Bradley et al. ${ }^{32}$ The second cycle presents a melting point and $\mathrm{T}_{\mathrm{g}}$ shows that the crystalline phase is continuous after heating in spite of an amorphous phase formation. The mesophases found for [DoDec(MIM)][Br] also appeared on [TetDec(MIM)] [Br] curve, however, it was not possible to observe the transitions from liquid to isotropic liquid in the first heating cycle, despite being found in the second cycle. This IL did not present $\mathrm{T}_{\mathrm{g}}$ (Figure 11 and Figure S14, SI section).

The $\left[\operatorname{BisAlk}(\mathrm{MIM})_{2}\right][2 \mathrm{Br}](\mathrm{n}=10,12$, and 14) have only an endothermic peak characteristic of the melting 
Table 3. Data from the thermal analyses obtained by DSC for ILs

\begin{tabular}{|c|c|c|c|c|c|c|c|}
\hline \multirow[b]{2}{*}{ IL } & \multicolumn{2}{|c|}{$1^{\text {st }}$ Heating cycle } & \multicolumn{5}{|c|}{$2^{\text {nd }}$ Heating cycle } \\
\hline & $\begin{array}{c}\mathrm{T}_{\mathrm{S}-\mathrm{SL}}{ }^{\mathrm{c}} / \\
\mathrm{K}\end{array}$ & $\begin{array}{l}\Delta \mathrm{H}^{\circ}{ }_{\mathrm{S}-\mathrm{SL}}^{\mathrm{d}} / \\
\left(\mathrm{kJ} \mathrm{mol}^{-1}\right)\end{array}$ & $\begin{array}{c}\mathrm{T}_{\mathrm{S}-\mathrm{SL}}{ }^{\mathrm{C}} / \\
\mathrm{K}\end{array}$ & $\begin{array}{l}\Delta \mathrm{H}^{\circ}{ }_{\mathrm{S} S \mathrm{SL}}{ }^{\mathrm{d}} / \\
\left(\mathrm{KJ} \mathrm{mol}^{-1}\right)\end{array}$ & $\begin{array}{c}\mathrm{T}_{\mathrm{SLLLI}}{ }^{\mathrm{e}} / \\
\mathrm{K}\end{array}$ & $\begin{array}{l}\Delta \mathrm{H}^{\circ}{ }_{\text {SL-LI }}^{\mathrm{f}} / \\
\left(\mathrm{KJ} \mathrm{mol}^{-1}\right)\end{array}$ & $\begin{array}{c}\mathrm{T}_{\mathrm{g}}^{\mathrm{g}} / \\
\mathrm{K}\end{array}$ \\
\hline$[\operatorname{Dec}(\mathrm{MIM})][\mathrm{Br}]^{\mathrm{a}}$ & 332 & 37 & - & - & - & - & 216 \\
\hline$[\mathrm{DoDec}(\mathrm{MIM})][\mathrm{Br}]^{\mathrm{a}}$ & 313 & 39 & 274 & 11 & 369 & 0.60 & 238 \\
\hline$[\operatorname{TetDec}(\mathrm{MIM})][\mathrm{Br}]^{\mathrm{a}}$ & 331 & 57 & 316 & 22 & 439 & 0.93 & - \\
\hline$\left[\operatorname{BisDec}(\mathrm{MIM})_{2}\right][2 \mathrm{Br}]^{\mathrm{b}}$ & $417^{\mathrm{h}}$ & $42^{\mathrm{i}}$ & - & - & - & - & 254 \\
\hline$\left[\operatorname{BisDoDec}(\mathrm{MIM})_{2}\right][2 \mathrm{Br}]^{\mathrm{b}}$ & $313^{\mathrm{h}}$ & $40^{\mathrm{i}}$ & - & - & - & - & 255 \\
\hline$\left.[\text { BisTetDec(MIM) })_{2}\right][2 \mathrm{Br}]^{\mathrm{b}}$ & $336^{\mathrm{h}}$ & $56^{\mathrm{i}}$ & - & - & - & - & 262 \\
\hline
\end{tabular}

${ }^{a}$ Monocationic ILs, 1-(3-methylimidazolium-1-yl)alkane ([Alk(MIM)][Br] where Alk = Dec, DoDec, TetDec); bdicationic ILs, 1,n-bis(3-methylimidazolium-

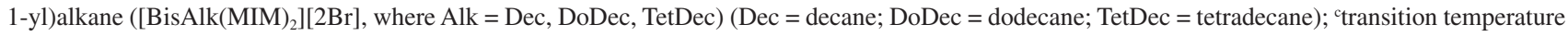
crystalline solid (S) to smetic liquid (SL); ${ }^{d}$ molar enthalpy of crystalline solid (S) transition to smetic liquid (SL); ${ }^{e}$ transition temperature of smetic liquid (SL) for isotropic liquid (LI); ${ }^{\mathrm{f}}$ molar enthalpy of transition of smetic liquid (SL) for isotropic liquid (LI); ${ }^{\mathrm{g} g l a s s}$ transition temperature; ${ }^{\mathrm{h}}$ melting temperature; imelting molar enthalpy.

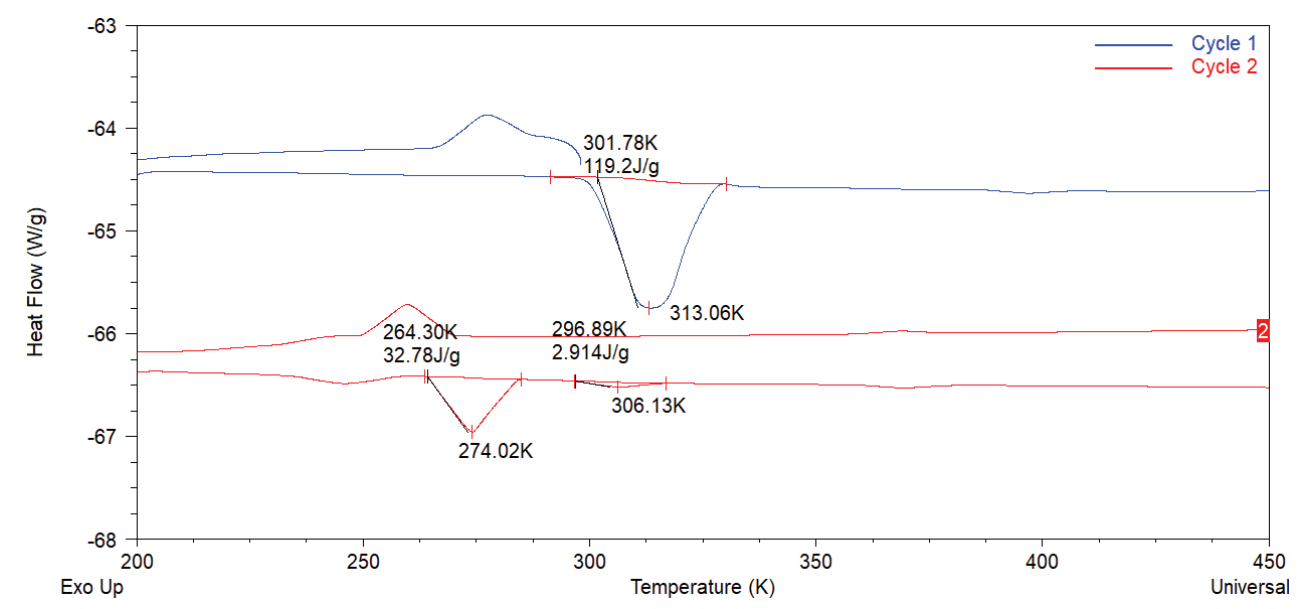

Figure 11. DSC curves of IL [DoDec(MIM)][Br] for first heating cycle (blue line) and second heating cycle (red line).

temperature (no crystallization peak was observed) in the first heating cycle. The ILs [BisDoDec(MIM) $\left.)_{2}\right][2 \mathrm{Br}]$ and $\left[\right.$ BisTetDec $\left.(\mathrm{MIM})_{2}\right][2 \mathrm{Br}]$ exhibit a second endothermic peak that may be assigned to a liquid-liquid transition of the smectic type for isotropic, as seen for monocationic ILs. $^{22}$ Furthermore, $\mathrm{T}_{\mathrm{g}}$ increases with increasing alkyl chain length for the $\left[\operatorname{BisAlk}(\mathrm{MIM})_{2}\right][2 \mathrm{Br}](\mathrm{n}=10,12$, and 14), seen in the second heating cycle. This can be explained by considering that the increased length of the alkyl chains increased the van der Waals interactions of attraction between the hydrophobic segments of the long chain..$^{23}$

It is important to note that all monocationic as well as the dicationic [TetDec(MIM) $\left.)_{2}\right][2 \mathrm{Br}]$ ILs exhibit crystallization when cooled in the second or first cycle. The other two dicationic ILs, [Dec(MIM) $\left.)_{2}\right][2 \mathrm{Br}]$ and $\left[\operatorname{DoDec}(\mathrm{MIM})_{2}\right][2 \mathrm{Br}]$, did not exhibit crystallization (see DSC curves in the SI section).

\section{Conclusions}

The phase transitions, thermal stability, thermokinetics, and activation parameters of degradation reactions of monoand dicationic imidazolium-based ILs were reported.

In general, we observed that both alkyl chain lengths and additional imidazolium ring in the IL structures promote pronounced changes in thermal degradation. The dicationic ILs are more stable than monocationic and thermal degradation of mono- and dicationic ILs did not show linear dependence of the alkyl chain length. The thermokinetic parameters obtained by the O-W-F and Friedman methods showed that the variation of Ea and $\ln \mathrm{A}$ as the fraction of mass conversion $(\alpha)$ was not linear, indicating a multiple-step mechanism. The $\Delta \mathrm{H}^{\ddagger}$ (energy necessary to promote the decomposition) for the mono- and dicationic ILs was in the $101-185 \mathrm{~kJ} \mathrm{~mol}^{-1}$ range. These results showed that the decomposition reactions of the ILs are endothermic. The transition phase of monocationic 
ILs was similar to ILs previously reported. However, the dicationic IL melted in the first heating cycle and became amorphous after heating. These data allow researchers to determine specific applications for ILs such as, for example, lubricants or solvents at high temperatures without losing their physical and chemical properties, since such data can estimate energy and temperature for correct application and safe keeping the initial characteristics to which these compounds were developed.

\section{Supplementary Information}

Overlay of TGA thermograms at different heating rates, graphs, curves that relate $\ln \beta v s .1 / \mathrm{T}$ and Ea $v s . \alpha v s . \ln \mathrm{A}$ by the Ozawa-Wall-Flyn method, curves that relate $\ln (\beta \mathrm{d} \alpha / \mathrm{dT}) v s .1 / \mathrm{T}$ and Ea $v$ s. $\alpha$ vs. In A by the Friedman method, and DSC curves of monocationic and dicationic imidazolium-based ionic liquids are available free of charge at http://jbcs.sbq.org.br as a PDF file.

\section{Acknowledgments}

The authors thank the National Council of Scientific and Technological Development (Conselho Nacional de Desenvolvimento Cientifíco e Tecnológico, CNPq), grant Nos. 432201/2018-1 and 306389/2018-5, and the Rio Grande do Sul State Foundation for Research Support (Fundação de Amparo à Pesquisa do Estado do Rio Grande do Sul, FAPERGS), grant No. 17/2551-0000944-4, for the finacial support. Fellowships from CNPq (C. P. F. and C. R. B.) and CAPES (B. L. K., T. S. B., F. I. Z.) are also acknowledged.

\section{References}

1. Coronas, A.; Salgado, J.; Villanueva, M.; Garcia, J.; Ind. Eng. Chem. Res. 2013, 52, 15718.

2. Martins, M. A. P.; Frizzo, C. P.; Tier, A. Z.; Moreira, D. N.; Zanatta, N.; Bonacorso, H. G.; Chem. Rev. 2014, 114, PR1.

3. Passerini, S. S.; Energy Environ. Sci. 2015, 9, 49.

4. Frizzo, C. P.; Bender, C. R.; Gindri, I. D. M.; Villetti, M. A.; Machado, G.; Bianchi, O.; Martins, M. A. P.; J. Phys. Chem. C 2016, 120, 14402.

5. Frizzo, C. P.; Bender, C. R.; Gindri, I. M.; Salbego, P. R. S.; Villetti, M. A.; Martins, M. A. P.; Colloid Polym. Sci. 2015, 293, 2901.

6. Steudte, S.; Bemowsky, S.; Mahrova, M.; Bottin-Weber, U.; Tojo-Suarez, E.; Stepnowski, P.; Stolte, S.; RSC Adv. 2014, 4, 5198.

7. Moosavi, M.; Khashei, F.; Sharifi, A.; Mirzaei, M.; J. Chem. Thermodyn. 2017, 107, 1.
8. Gao, J.; Yao, S.; Wang, Y.; Hou, Z.; Yang, C.; Song, H.; New J. Chem. 2018, 42, 11539.

9. Martins, M. A. P.; Marzari, M. R. B.; Frizzo, C. P.; Zanatta, M.; Buriol, L.; Andrade, V. P.; Zanatta, N.; Bonacorso, H. G.; Eur. J. Org. Chem. 2012, 3, 7112.

10. Frizzo, C. P.; Gindri, I. M.; Bender, C. R.; Tier, A. Z.; Villetti, M. A.; Rodrigues, D. C.; Machado, G.; Martins, M. A. P.; Colloids Surf., A 2015, 468, 285.

11. Yu, G.; Yan, S.; Zhou, F.; Liu, X.; Liu, W.; Liang, Y.; Tribol. Lett. 2007, 25, 197.

12. Gindri, I. M.; Siddiqui, D. A.; Davis, C.; Frizzo, C. P.; Martins, M. A. P.; Rodrigues, D. C.; RSC Adv. 2016, 6, 78795.

13. Gindri, I. M.; Frizzo, C. P.; Bender, C. R.; Tier, A. Z.; Martins, M. A. P.; Villetti, M. A.; Machado, G.; Rodriguez, L. C.; Rodrigues, D. C.; ACS Appl. Mater. Interfaces 2014, 6, 11536.

14. Maton, C.; De Vos, N.; Stevens, C. V.; Chem. Soc. Rev. 2013, 42, 5963.

15. Del Sesto, R. E.; McCleskey, T. M.; Macomber, C.; Ott, K. C.; Koppisch, A. T.; Baker, G. A.; Burrell, A. K.; Thermochim. Acta 2009, 491, 118.

16. Kamavaram, V.; Reddy, R. G.; Int. J. Therm. Sci. 2008, 47, 773.

17. Hao, Y.; Peng, J.; Hu, S.; Li, J.; Zhai, M.; Thermochim. Acta 2010, 501, 78 .

18. Muhammad, A.; Pol. J. Chem. Technol. 2016, 2, 122.

19. Frizzo, C. P.; Villetti, M. A.; Tier, A. Z.; Gindri, I. M.; Buriol, L.; Rosa, F. A.; Claramunt, R. M.; Sanz, D.; Martins, M. A. P.; Thermochim. Acta 2013, 574, 63.

20. Brown, M. E.; Maciejewski, M.; Vyazovkin, S.; Nomen, R.; Sempere, J.; Burnham, A.; Opfermann, J.; Strey, R.; Anderson, H. L.; Kemmler, A.; Keuleers, R.; Janssens, J.; Desseyn, H. O.; Li, C.-H.; Tang, T. B.; Roduit, B.; Malek, J.; Mitsuhashi, T.; Thermochim. Acta 2000, 355, 125.

21. Shirota, H.; Mandai, T.; Fukazawa, H.; Kato, T.; J. Chem. Eng. Data 2011, 56, 2453.

22. Inoue, T.; Ebina, H.; Dong, B.; Zheng, L.; J. Colloid Interface Sci. 2007, 314, 236.

23. Souza, D.; Castillo, T. E.; Rodríguez, R. J. S.; Matéria 2009 , $14,946$.

24. Arellano, I. H. J.; Guarino, J. G.; Paredes, F. U.; Arco, S. D.; J. Therm. Anal. Calorim. 2011, 103, 725.

25. Frizzo, C. P.; Bender, C. R.; Salbego, P. R. S.; Farias, C. A. A.; da Silva, T. C.; Stefanello, S. T.; da Silveira, T. L.; Soares, F. A. A.; Villetti, M. A.; Martins, M. A. P.; ACS Omega 2018, 3,734 .

26. Khan, A. S.; Man, Z.; Bustam, M. A.; Kait, C. F.; Ullah, Z.; Sarwono, A.; Wilfred, C. D.; Procedia Eng. 2016, 148, 1332.

27. Zhang, H.; Wu, J.; Zhang, J.; He, J.; Macromolecules 2005, 38 , 8272.

28. Shamsipur, M.; Pourmortazavi, S. M.; Beigi, A. A. M.; Heydari, R.; Khatibi, M.; AAPS PharmSciTech 2013, 14, 287. 
29. Anslyn, E. V.; Dougherty, D. A.; Modern Physical Organic Chemistry, $1^{\text {st }}$ ed.; Murdzek, J., ed.; University Science Books: Mill Valley, California, 2006.

30. Heym, F.; Etzold, B. J. M.; Kern, C.; Jess, A.; Green Chem. 2011, 13, 1453.

31. Zhu, J.; Bai, L.; Chen, B.; Fei, W.; Chem. Eng. J. 2009, 147, 58.
32. Bradley, A. E.; Hardacre, C.; Holbrey, J. D.; Johnston, S.; Mcmath, S. E. J.; Nieuwenhyzen, M.; Chem. Mater. 2002, 14, 629.

Submitted: February 7, 2019

Published online: May 24, 2019 